\title{
Polymorphisms in estrogen receptor- $\alpha$ are associated with idiopathic female infertility
}

\author{
JIU-WEI DU, XIN-RONG TAO, KE-YI XU, LI-YI FANG and XIN-LAN QI \\ School of Medicine, Anhui University of Science and Technology, Huainan, Anhui 232001, P.R. China
}

Received April 28, 2011; Accepted August 8, 2011

DOI: $10.3892 / \mathrm{mmr} .2011 .551$

\begin{abstract}
To investigate the relationship between polymorphisms in the estrogen receptor- $\alpha(\mathrm{ER} \alpha)$ gene and unexplained female infertility, restriction fragment length polymorphism (RFLP) analysis of ER $\alpha$ was employed in 150 females with idiopathic infertility (study group) and 150 healthy, age-matched females of proven fertility (control group). The results showed that the ER $\alpha$ allele frequencies differed significantly between the study and control groups $(\mathrm{P}=0.001)$. The allele identified by $P v u \mathrm{II}(\mathrm{P})$ restriction was detected more frequently in the study group (49.0\% of individuals) compared to the control group $(31.0 \%$; $\mathrm{P}=0.001)$, while the allele identified by $\mathrm{XbaI}(\mathrm{X})$ restriction was detected less frequently in the study group (19.7\%) compared to the control group $(35.7 \%$, $\mathrm{P}=0.001)$. A similar phenomenon was observed for the distribution of the TA alleles. The TA13 allele was more common in the study group ( 24.7 vs. $6.7 \%$ in controls; $\mathrm{P}=0.001)$, while the TA15 allele was less common in the study group (15.3 vs. $27.3 \%$ in controls; $\mathrm{P}=0.034$ ). To conclude, polymorphisms in the ER $\alpha$ gene are associated with idiopathic female infertility. In particular, the $\mathrm{P}$ and TA13 alleles may represent significant risk factors, while the $\mathrm{X}$ and TA15 alleles may be protective factors.
\end{abstract}

\section{Introduction}

Idiopathic female infertility refers to an inability or difficulty to conceive resulting from unexplained causes. Indeed, upon standard examination, no abnormalities are observed in sex hormone levels and no surgical or congenital diseases are indicated (1). Additionally, the male partner is observed to have normal fertility. However, hysteroscopy reveals a thinner endometrium exhibiting stunted growth, which is inconsistent with the traditional explanation of endometrial damage and scarring (1).

Correspondence to: Dr Jiu-Wei Du, School of Medicine, Anhui University of Science and Technology, 25 Dongshanzhong Road, Huainan, Anhui 232001, P.R. China

E-mail: djwdxswy@126.com

Key words: infertility, estrogen receptor, gene polymorphism, dinucleotide repeat sequence, allelic variant
Certain data indicate reduced estrogen receptor (ER) expression in females with unexplained infertility (2). ERs are nuclear hormone receptors activated by estradiol, a critical reproductive hormone (3). Single nucleotide polymorphisms (SNPs) of ER $\alpha$, which is encoded by ESR1, may alter transcription or translation, leading to abnormal expression of the protein (4). Indeed, polymorphisms in this gene that are detected through $P v u I I$ or $\mathrm{XbaI}$ restriction digestion have been associated with disorders affecting bone density (5) and lipid metabolism (6). Furthermore, a regulatory region upstream of the ER $\alpha$ coding sequence contains a dinucleotide (TA) repeat, which appears to affect ER $\alpha$ expression (7), and polymorphisms in a number of these repeats have been associated with fracture risk in osteoporosis (8). Significantly, a recent study observed specific associations between ER $\alpha$ polymorphisms and oocyte maturation and fertilization rates in infertile females undergoing in vitro fertilization (9). Due to these suggestive findings, we investigated ER $\alpha$ gene polymorphisms in females with idiopathic infertility to determine whether potential allelic variants may contribute to infertility.

\section{Materials and methods}

Study participants. The present study included 150 female patients diagnosed with unexplained infertility at the Affiliated Hospital, School of Medicine, Anhui University of Science and Technology between January 2008 and December 2010. These patients ranged in age from 24 to 43 years, with a mean age of $31.2 \pm 6.8$ years. To be included in the study, patients were required to have a normal menstrual cycle and normal circulating levels of sex hormones. The male partner was required to exhibit no sexual dysfunction, no abnormalities upon genital examination and have two normal routine semen examinations. Additionally, by hysteroscopy, the endometrium of the patients had to be smooth, thin and lacking adhesions, and the fallopian tube opening had to be clearly visible on day 5 of the menstrual period. By ultrasonography, endometrial thickness had to be $<7 \mathrm{~mm}$. Patients were included if no reproductive or anatomic abnormality was observed during gynecological or pelvic B ultrasound examination, and recent (previous 6 months) lipiodol angiography or laparoscopy must have indicated smoothness of the two fallopian tubes. Finally, prior to examination, patients had not received any previous hormone therapy and ovulated within the previous 3 months. The presence of the following diseases excluded patients from 
the study: diabetes, tuberculosis, thyroid and adrenal glandular disease, other endocrine diseases, surgical diseases and congenital diseases. Another 150 healthy females receiving a physical examination during the same period were enrolled as controls. Their ages ranged from 22 to 35 years, with a mean age of $28.5 \pm 5.6$ years. Females having a normal menstrual volume, cycle and sex hormone levels, not receiving any sex hormone therapy, exhibiting normal reproductive and endometrium anatomy by pelvic B ultrasonography and having been previously pregnant were included as controls. The mean ages of the study population and controls were not significantly different $(\mathrm{P}>0.05)$.

DNA extraction. DNA was extracted from $2 \mathrm{ml}$ of fasting blood samples from each patient using a DNA extraction kit provided by Sangon Biotech Co., Ltd. (Shanghai, China), according to the manufacturer's instructions. DNA samples were resuspended in Tris-EDTA (TE) buffer.

PCR amplification. DNA amplification was performed by PCR using primers synthesized by Sangon Biotech Co., Ltd. for ER $\alpha$ : forward, 5'-CTG CCA CCC TAT CTG TAT CTT TTC CTA TTC TCC-3' and reverse, 5'-TCT TTC TCT GCC ACC CTG GCG TCG ATT ATC TGA-3'; and for the TA repetitive sequence: forward, 5'-GAC GCA TGA TAT ACT TCA CC-3' and reverse, 5'-GCA GAA TCA AAT ATC CAG ATG-3'. Reaction mixtures contained 5.0 $\mu \mathrm{l}$ 10X buffer (15 mM MgCl2), $4.0 \mu \mathrm{l} \mathrm{dNTP}(200 \mu \mathrm{M} / 1), 1.0 \mu \mathrm{l}$ of each primer $(25 \mathrm{pM} / \mu \mathrm{l}), 0.5 \mu \mathrm{l}$ Taq DNA polymerase $(5 \mathrm{U} / \mu \mathrm{l})$ and $4 \mu$ 1 DNA template, diluted with water to a total volume of $50 \mu \mathrm{l}$. Reaction conditions were as follows: (i) $94^{\circ} \mathrm{C}, 5 \mathrm{~min}$; (ii) $94^{\circ} \mathrm{C}$ for $35 \mathrm{sec}, 58^{\circ} \mathrm{C}$ for $50 \mathrm{sec}$, and $72^{\circ} \mathrm{C}$ for $90 \mathrm{sec}$ for 32 cycles; and (iii) $72^{\circ} \mathrm{C}$ for $10 \mathrm{~min}$. Amplified DNA was separated on a $1 \%(\mathrm{ER} \alpha)$ or $2 \%$ (TA) agarose gel, stained with ethidium bromide and visualized with ImageMaster ${ }^{\circledR}$ VDS. For restriction digests to detect polymorphisms, separate $10-\mu 1$ aliquots of ER $\alpha$ PCR products were exposed to $10 \mathrm{U} P v u \mathrm{II}$ or $20 \mathrm{U} \mathrm{XbaI}$ at $37^{\circ} \mathrm{C}$ for $4 \mathrm{~h}$. Digested products were separated on a $2 \%$ agarose gel and visualized with a GEL DOC1000 image analyzer (Bio-Rad, Hercules, CA, USA).

Statistical methods. SPSS 13.0 statistical software was used for statistical analysis. The RxC contingency table analysis $\chi 2$ test was used to analyze distribution frequency of the inter-group $P v u I I, X b a \mathrm{I}$ and TA repeat alleles. The 4 -fold table $\chi 2$ test was used to compare the frequency of the inter-group $P v u \mathrm{II}, X b a \mathrm{I}$ and TA repeat alleles. Relative risk was expressed by odds ratio (OR). All analyses used 2-sided tests, with $\alpha=0.05$ considered to be statistically significant.

\section{Results}

PvuII and XbaI genotypes differ between infertile females and controls. Consistent with previous findings, polymorphisms in $\mathrm{ER} \alpha$ were detected via restriction digestion of the amplified gene with $P v u I I$ and $X b a I$ endonucleases (10). PvuII digestion yielded products of $1300 \mathrm{bp}$ ( $\mathrm{P}$ allele) or 450 and $850 \mathrm{bp}(\mathrm{p}$ allele), giving 3 possible genotypes: PP (1300 bp); Pp (1300, 450 and $850 \mathrm{bp}$ ); and pp (450 and $850 \mathrm{bp}$; Fig. 1). Similarly, XbaI digestion yielded products of $1300 \mathrm{bp}$ (X allele) or 400 and

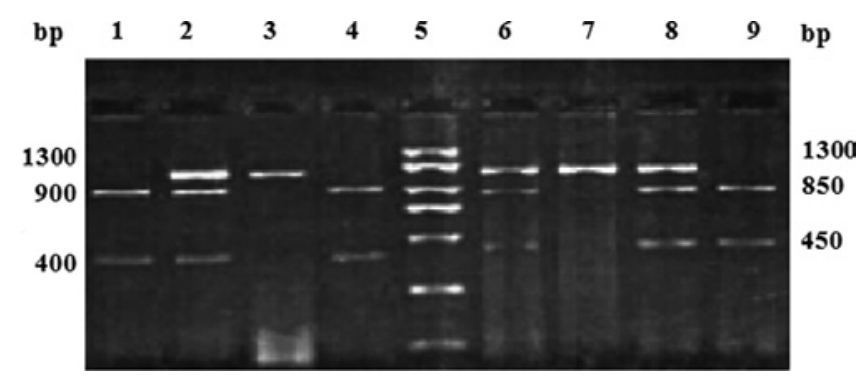

Figure 1. Polymorphisms of the estrogen receptor (ER) digested by enzymes $P v u \mathrm{II}$ and $\mathrm{XbaI}$. Lane 1 and 4, Xx genotype; lane 2, Xx; lane 3, XX; lane 6 and 8, Pp genotype; lane 7, PP genotype; lane 9, pp genotype.

900 bp (x allele), giving 3 possible genotypes: XX (1300 bp); Xx (1300, 400 and 900 bp); and Xx (400 and 900 bp; Fig. 1).

The frequency of $P v u I I$ and $X b a I$ genotypes in the study and control groups reached Hardy-Weinberg equilibrium and were representative of the group. The difference in distribution of $P v u I I$ genotypes between the two groups was statistically significant $(\chi 2=24.992, \mathrm{P}=0.001)$. Indeed, the $\mathrm{P}$ allele frequency in the study group $(49.0 \%)$ was significantly higher compared to that of the control group (31.0\%, $\mathrm{P}=0.001)$, with an OR of 2.139 (95\% CI, 1.532-2.985; Table I). Similarly, the distribution of $\mathrm{XbaI}$ genotypes was significantly different between the two groups $(\chi 2=28.612, P=0.001)$. The $\mathrm{X}$ allele frequency in the study group (19.7\%) was significantly lower compared to that in the control group $(35.7 \%, \mathrm{P}=0.001)$, with an OR of 0.442 (95\% CI, 0.305-0.639; Table II).

TA repeats vary between infertile females and controls. PCR amplification of the upstream region of ER $\alpha$ produced products of $200 \mathrm{bp}$ in size (Fig. 2). We identified 6 (TA) genotypes, called TA11-TA16 (Table III). The distribution of the (TA)n repetitive sequence alleles differed significantly between the study and control groups $(\chi 2=26.491, \mathrm{P}=0.001)$. In particular, TA13 was more common in infertile females [24.7 vs. $6.7 \%$ of the controls, $\mathrm{P}=0.001 ; \mathrm{OR}=4.584$ (95\% CI 2.184-9.620)], while TA15 was less common in these females [15.3 vs. $27.3 \%$ of the controls, $\mathrm{P}=0.034$; $\mathrm{OR}=0.481$ (95\% CI 0.272-0.852)]. The other (TA)n allele frequencies did not significantly differ between the groups $(\mathrm{P}>0.05)$.

\section{Discussion}

Unexplained infertility accounts for $10-20 \%$ of all infertility (1). Unexplained female infertility is diagnosed when clinical examination shows no abnormalities in ovulatory function, the fallopian tubes are unobstructed and the male partner exhibits normal sperm (1). In these infertile patients, hysteroscopy shows thin endometria, manifested as poor growth and development.

Estrogen is the main hormone regulating endometrial growth. However, this hormone requires the activity of ERs to be effective (11), thus, any alterations in ER expression may also affect the function of estrogen. SNPs have been identified in the two genes encoding ERs, ESR1 and ESR2 (encoding $\mathrm{ER} \alpha$ and $\mathrm{ER} \beta$, respectively), which alter their expression (3). Most studies of ER SNPs have focused on their roles in breast cancer (12), osteoporosis (13) and prostate cancer (14). 
Table I. Distributions of PvuII genotypes and alleles in the study and control groups.

\begin{tabular}{|c|c|c|c|c|c|c|}
\hline \multirow[t]{2}{*}{ Group } & \multirow[t]{2}{*}{ No. } & \multicolumn{3}{|c|}{ Genotype frequency n $(\%)$} & \multicolumn{2}{|c|}{ Allele frequency n (\%) } \\
\hline & & PP & $\mathrm{Pp}$ & $\mathrm{pp}$ & $\mathrm{P}$ & $\mathrm{p}$ \\
\hline Study & 150 & $29(19.3)$ & $89(59.3)$ & $32(21.3)$ & $147(49.0)$ & $153(51.0)$ \\
\hline Control & 150 & $16(10.7)$ & $61(40.7)$ & $73(48.7)$ & $93(31.0)$ & $207(69.0)$ \\
\hline$\chi^{2}$ & & 24.992 & & & 20.250 & \\
\hline P-value & & 0.001 & & & 0.001 & \\
\hline OR & & & & & 2.139 & \\
\hline
\end{tabular}

Table II. Distributions of $X b a \mathrm{I}$ genotypes and alleles in the study and control groups.

\begin{tabular}{|c|c|c|c|c|c|c|}
\hline \multirow[t]{2}{*}{ Group } & \multirow[t]{2}{*}{ No. } & \multicolumn{3}{|c|}{ Genotype frequency n (\%) } & \multicolumn{2}{|c|}{ Allele frequency n (\%) } \\
\hline & & $\mathrm{XX}$ & $\mathrm{Xx}$ & $\mathrm{xx}$ & $\mathrm{X}$ & $\mathrm{x}$ \\
\hline Study & 150 & $6(4.0)$ & $47(31.3)$ & $97(64.7)$ & $59(19.7)$ & $241(80.3)$ \\
\hline Control & 150 & $8(5.3)$ & $91(60.7)$ & $51(34.0)$ & $107(35.7)$ & $193(64.3)$ \\
\hline$\chi^{2}$ & & 28.612 & & & 19.188 & \\
\hline P-value & & 0.001 & & & 0.001 & \\
\hline OR & & & & & 0.442 & \\
\hline
\end{tabular}

Table III. Allele frequencies of the (TA $)_{n}$ repeat sequence in the study and control groups, no. (\%).

\begin{tabular}{lccccccc}
\hline Group & TA11 & TA12 & TA13 & TA14 & TA15 & TA16 & $\chi^{2}$ \\
\hline Study & $3(2.0)$ & $13(8.7)$ & $37(24.7)$ & $34(22.8)$ & $23(15.3)$ & $16(10.7)$ & 26.491 \\
Control & $1(0.7)$ & $7(4.7)$ & $10(6.7)$ & $45(30.0)$ & $41(27.3)$ & $24(16.0)$ & 0.001 \\
$\chi^{2}$ & 1.014 & 1.333 & 15.789 & 2.286 & 4.511 & 1.330 & 0.249 \\
P-value & 0.314 & 0.248 & 0.001 & 0.131 & 0.034 & 0.682 \\
OR & 3.041 & 1.568 & 3.500 & 0.682 & 0.565 & \\
\hline
\end{tabular}

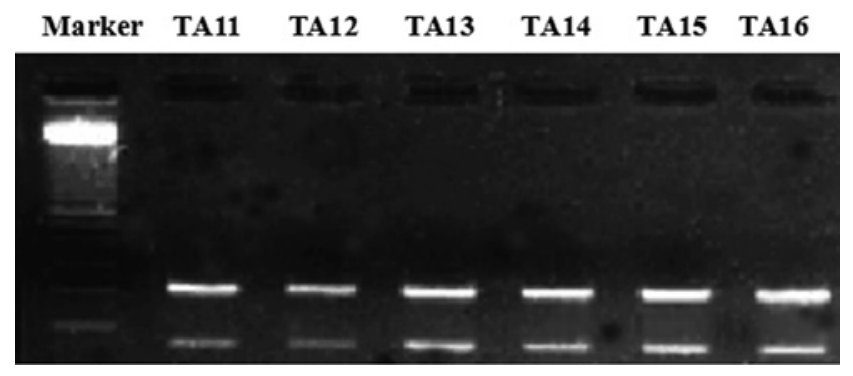

Figure 2. Electrophoretogram analysis of the amplified products of the (TA) repeat sequence.

However, little information exists to describe the role of ER polymorphisms in unexplained infertility. Recently, Ayvaz et al reported an association between polymorphisms in ER $\alpha$ and ovulation and fertilization rates in females undergoing in vitro fertilization (9). This finding suggests that ER $\alpha$ dysfunction may affect female fertility.
Indeed, when considered in the context of endometrial thinning, ER becomes an attractive candidate for idiopathic infertility. We hypothesize that, due to under-activity of ER, target tissues exhibit a reduced response to estrogen, causing them to exhibit lower rates of proliferation. Poor local tissue proliferation would result in thinning of the endometrium, which, in turn, would affect implantation of fertilized ova and cause infertility. Specific evidence indicates that polymorphisms identified in ER $\alpha$ through $P v u I I$ and $X b a I$ restriction are associated with reduced ER $\alpha$ expression, which has been found in patients with thinner endometria.

Our study of polymorphisms in ER $\alpha$ shows that $P v u \mathrm{II}$ and $X b a I$ alleles differ significantly between females with idiopathic infertility and healthy females with proven fertility. Indeed, the $\mathrm{P}$ allele is more common $(\mathrm{OR}=2.139)$ in infertile than in fertile females, while the $\mathrm{X}$ allele is less common $(\mathrm{OR}=0.442)$. Thus, polymorphisms in ER $\alpha$ are associated with idiopathic female infertility, with the $\mathrm{P}$ allele potentially acting as a risk factor and the $\mathrm{X}$ allele acting as a protective factor.

The regulatory region upstream of the ER $\alpha$ coding region contains a TA repetitive sequence, which may influence ER 
expression (15). Polymorphisms in this region have been associated with endometriosis (15). Thus, we compared (TA)n repeats among females with idiopathic infertility and healthy, fertile females and confirmed 6 alleles. The (TA)n allele frequencies differ significantly between these groups. Indeed, in infertile females the TA13 allele is significantly more common $(\mathrm{OR}=4.584)$, compared to the TA15 allele $(\mathrm{OR}=0.481)$. Therefore, polymorphisms in this ER gene regulatory region are associated with idiopathic female infertility, with the TA13 allele acting as a potential risk factor and the TA15 allele acting as a protective factor.

In conclusion, ER $\alpha$ gene polymorphisms may be useful as predictors of idiopathic female infertility. While providing a theoretical basis for the clinical diagnosis and treatment of idiopathic infertility, the number of patients enrolled in this study was small. Therefore, further analysis with a larger cohort is required to confirm whether these polymorphisms represent serious risk factors.

\section{References}

1. Spira A: Epidemiology of human reproduction. Hum Reprod 1: $111-115,1986$

2. Haller K, Salumets A, Grigorova M, et al: Putative predictors of antibodies against follicle-stimulating hormone in female infertility: a study based on in vitro fertilization patients. Am J Reprod Immunol 57: 193-200, 2007.

3. Figtree GA, Noonan JE, Bhindi R and Collins P: Estrogen receptor polymorphisms: significance to human physiology, disease and therapy. Recent Pat DNA Gene Seq 3: 164-171, 2009.

4. Nilsson M, Naessen S, Dahlman I, Linden Hirschberg A Gustafsson JA and Dahlman-Wright K: Association of estrogen receptor $\beta$ gene polymorphisms with bulimic disease in women. Mol Psychiatry 9: 28-34, 2004

5. Ivanova JT, Doukova PB, Boyanov MA and Popivanov PR: PvuII and $\mathrm{XbaI}$ polymorphisms of the estrogen receptor gene and bone mineral density in a Bulgarian population sample. Hormones (Athens) 6: 36-43, 2007.
6. Molvarec A, Nagy B, Kovacs M, et al: Lipid, haemostatic and inflammatory variables in relation to the estrogen receptor $\alpha$ (ESR1) PvuII and XbaI gene polymorphisms. Clin Chim Acta 380: 157-164, 2007.

7. Sundermann EE, Maki PM and Bishop JR: A review of estrogen receptor $\alpha$ gene $(E S R I)$ polymorphisms, mood, and cognition. Menopause 17: 874-886, 2010.

8. Langdahl BL, Lokke E, Carstens M, Stenkjaer LL and Eriksen EF: A TA repeat polymorphism in the estrogen receptor gene is associated with osteoporotic fractures but polymorphisms in the first exon and intron are not. J Bone Miner Res 15: 2222-2230, 2000.

9. Ayvaz OU, Ekmekci A, Baltaci V, Onen HI and Unsal E: Evaluation of in vitro fertilization parameters and estrogen receptor $\alpha$ gene polymorphisms for women with unexplained infertility. J Assist Reprod Genet 26: 503-510, 2009.

10. Corbo RM, Gambina G, Ruggeri M and Scacchi R: Association of estrogen receptor $\alpha$ (ESR1) PvuII and XbaI polymorphisms with sporadic Alzheimer's disease and their effect on apolipoprotein E concentrations. Dement Geriatr Cogn Disord 22: 67-72, 2006.

11. Sato H, Nogueira-de-Souza NC, D'Amora P, Silva ID, Girao MJ and Schor E: Intron 1 and exon $1 \alpha$ estrogen receptor gene polymorphisms in women with endometriosis. Fertil Steril 90: 2086-2090, 2008.

12. Georgopoulos NA, Adonakis GL, Fotopoulos A, et al: Estrogen receptor polymorphisms in tamoxifen-treated women with breast cancer. Gynecol Endocrinol 22: 185-189, 2006.

13. Gennari L, Merlotti D, De Paola V, et al: Estrogen receptor gene polymorphisms and the genetics of osteoporosis: a HuGE review. Am J Epidemiol 161: 307-320, 2005.

14. Gupta L, Thakur H, Sobti RC, Seth A and Singh SK: Role of genetic polymorphism of estrogen receptor- $\alpha$ gene and risk of prostate cancer in north Indian population. Mol Cell Biochem 335: 255-261, 2010.

15. Kim SH, Choi YM, Jun JK, Kim JG and Moon SY: Estrogen receptor dinucleotide repeat polymorphism is associated with minimal or mild endometriosis. Fertil Steril 84: 774-777, 2005. 